\title{
Medical Image of the Week: Scleroderma
}

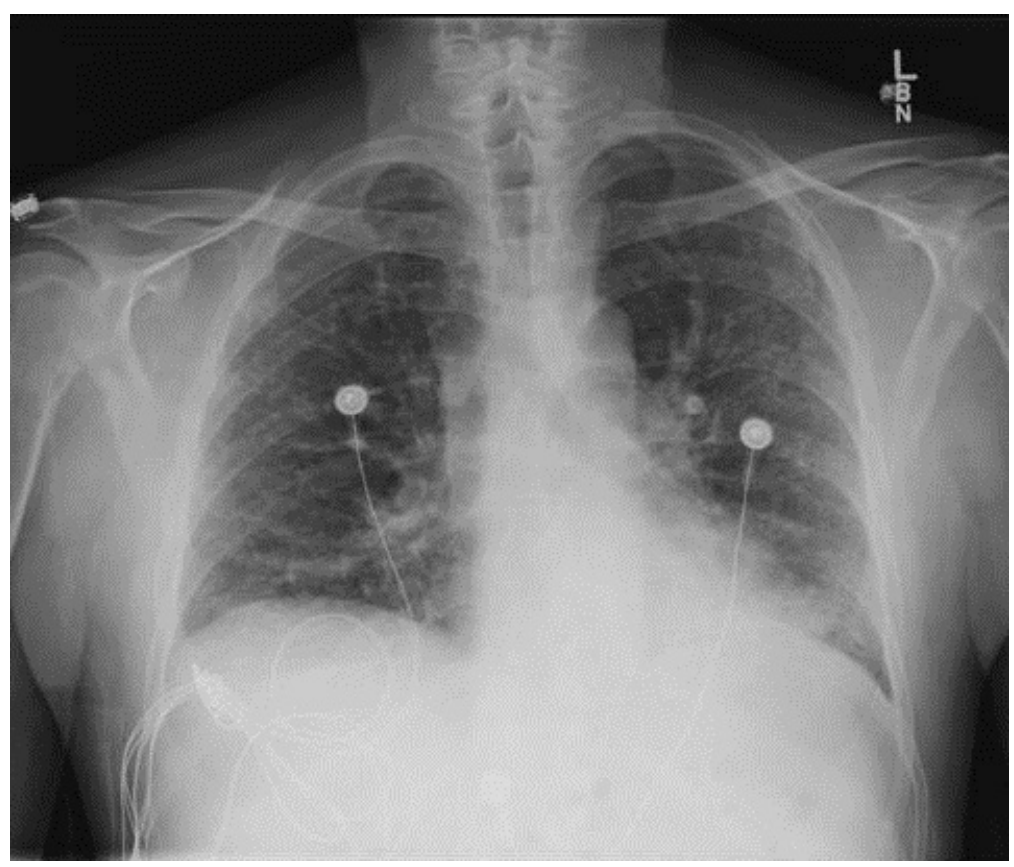

Figure 1. Frontal view of the chest shows shallow lung volumes with reticulation and bronchiolar dilatation, including slightly asymmetric basilar opacity, left greater than right most suggestive of interstitial lung disease.

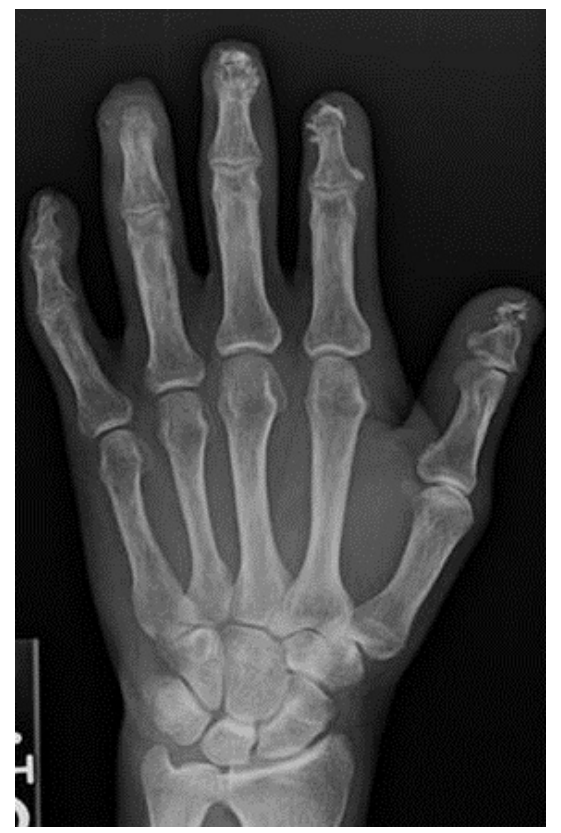

Figure 2. X-ray of the right hand performed 2 years prior to the chest $\mathrm{x}$-ray reveals distal tuft resorption and erosions in addition to distal subcutaneous calcifications. The finger tips also appear atrophied and tapered. 
A 56-year-old man presents with cough and dyspnea. Pertinent history is significant for scleroderma. A complete blood count and differential count were unremarkable. A chest radiograph was obtained (Figure 1). Based on overall imaging and clinical history, the chest $\mathrm{x}$-ray findings are highly suggest interstitial lung disease likely related to scleroderma and a recommendation for high resolution chest CT was made.

Progressive systemic sclerosis (scleroderma) is an autoimmune connective tissue disease that affects 30-50 year old women more often than men and is characterized by the overproduction of collagen which can lead to fibrosis which includes the lungs, skin, and may also affect visceral organs (1). In the hands, vasculitis and Raynaud's phenomenon may lead to distal tapering (2). Although acro-osteolysis or distal tuft resorption can be seen in a wide variety of disorders, it may be present in up to $80 \%$ of patients with scleroderma. High-resolution chest CT is helpful to characterize the degree of involvement and fibrosis which tends to be basilar and peripherally predominant and may include both usual interstitial pneumonia or nonspecific interstitial pneumonitis as common patterns.

Veronica A. Arteaga MD and Kenneth S. Knox MD Departments of Medical Imaging and Pulmonary and Critical Care University of Arizona Medical Center

Tucson, Arizona

\section{References}

1. Mayberry JP, Primack SL, Müller NL. Thoracic manifestations of systemic autoimmune diseases: radiographic and high-resolution CT findings. Radiographics. 2000;20(6):1623-35. [CrossRef] [PubMed]

2. Manaster BJ, May DA, Disler DG. Musculoskeletal Imaging, The Requisites, $4^{\text {th }}$ edition. Mosby, Elsevier. Chapter 20: Connective Tissue Disorders, pages 288-293. 